\title{
Deposition of $\mathrm{SiN}_{x}: \mathrm{H}$ thin films by the electron cyclotron resonance and its application to $\mathrm{Al} / \mathrm{SiN}_{x}: \mathrm{H} / \mathrm{Si}$ structures
}

\author{
S. Garcia, I. Martil, ${ }^{a)}$ and G. Gonzalez Diaz \\ Departamento Electricidad y Electronica, Facultad Fisicas, Universidad Complutense de Madrid, \\ 28040 Madrid, Spain \\ E. Castan and S. Dueñas \\ Departamento Electricidad y Electronica, Facultad Ciencias, Universidad de Valladolid, \\ 47011 Valladolid, Spain
}

\author{
M. Fernandez \\ Instituto de Ciencia de Materiales, Cantoblanco, 28049 Madrid, Spain
}

(Received 28 March 1997; accepted for publication 15 September 1997)

\begin{abstract}
We have analyzed the electrical properties and bonding characteristics of $\mathrm{SiN}_{x}: \mathrm{H}$ thin films deposited at $200^{\circ} \mathrm{C}$ by the electron cyclotron resonance plasma method. The films show the presence of hydrogen bonded to silicon (at the films with the ratio $\mathrm{N} / \mathrm{Si}<1.33$ ) or to nitrogen (for films where the ratio N/Si is higher than 1.33). In the films with the N/Si ratio of 1.38 , the hydrogen content is 6 at. \%. For compositions which are comprised of between $\mathrm{N} / \mathrm{Si}=1.1$ and 1.4 , hydrogen concentration remains below 10 at. \%. The films with $\mathrm{N} / \mathrm{Si}=1.38$ exhibited the better values of the electrical properties (resistivity, $6 \times 10^{13} \Omega \mathrm{cm}$; and electric breakdown field, $3 \mathrm{MV} / \mathrm{cm}$ ). We have used these films to make metal-insulator-semiconductor (MIS) devices on $n$-type silicon wafers. $C-V$ measurements accomplished on the structures indicate that the interface trap density is kept in the range $(3-5) \times 10^{11} \mathrm{~cm}^{-2} \mathrm{eV}^{-1}$ for films with the N/Si ratio below 1.38. For films where the $\mathrm{N} / \mathrm{Si}$ ratio is higher than 1.4 , the trap density suddenly increases, following the same trend of the concentration of $\mathrm{N}-\mathrm{H}$ bonds in the $\mathrm{SiN}_{x}: \mathrm{H}$ films. The results are explained on the basis of the model recently reported by Lucovsky [J. Vac. Sci. Technol. B 14, 2832 (1996)] for the electrical behavior of (oxide-nitride-oxide)/Si structures. The model is additionally supported by deep level transient spectroscopy measurements, that show the presence of silicon dangling bonds at the insulator/semiconductor interface (the so-called $P_{b \mathrm{~N} 0}$ center). The concentration of these centers follows the same trend with the film composition of the interface trap density and, as a consequence, with the concentration of $\mathrm{N}-\mathrm{H}$ bonds. This result further supports the $\mathrm{N}-\mathrm{H}$ bonds located at the insulator/semiconductor interface which act as a precursor site to the defect generation of the type - $\mathrm{Si} \equiv \mathrm{Si}_{3}$, i.e., the $P_{b \mathrm{~N} 0}$ centers. A close relation between interface trap density, $P_{b \text { No }}$ centers and $\mathrm{N}-\mathrm{H}$ bond density is established. (C) 1998 American Institute of Physics.
\end{abstract}

[S0021-8979(97)03724-9]

\section{INTRODUCTION}

The electron-cyclotron-resonance plasma method (ECR) has proved to be one of the most suitable deposition procedures to obtain insulator thin films. Device quality $\mathrm{SiN}_{x}: \mathrm{H},{ }^{1}$ $\mathrm{SiO}_{2},{ }^{2}$ and $\mathrm{SiO}_{x} \mathrm{~N}_{y},{ }^{3}$ have been deposited at a low substrate temperature with this technique.

There are reports on metal-insulator-semiconductor devices (MIS) with different semiconductors in which the insulator was deposited by the ECR plasma method. Structures such as $\mathrm{SiN}_{x} / \mathrm{InP}^{4}{ }^{4} \mathrm{SiN}_{x} / \mathrm{GaAs}^{1}{ }^{1}$ and $\mathrm{SiN}_{x} / \mathrm{InGaAs}$ (Ref. 5) have been described recently, with good interface characteristics. The good electrical behavior exhibited by these devices was attributed to the "soft" character of the ECR plasma method.

In the field of $\mathrm{Si}$ based MIS devices, the use of $\mathrm{SiN}_{x}: \mathrm{H}$ films has shown a growing interest. As device dimensions shrink below $0.1 \mu \mathrm{m}$ in ultralarge scale integrated circuits (ULSI), the thickness of the gate dielectric in field effect transistors (FETs) falls to the 3-4 $\mathrm{nm}$ range. In these ultra-

${ }^{a)}$ Electronic mail: imartil@eucmax.sim.ucm.es thin insulators, the incorporation of $\mathrm{SiN}_{x}: \mathrm{H}$ interlayers to the standard $\mathrm{SiO}_{2}$ dielectric film appears to be successful in order to improve gate performance. ${ }^{6,7}$ Gate dielectric structures of the type oxide/nitride/oxide have shown excellent characteristics that allow them to be used in ULSI circuits. ${ }^{8}$ The analysis of these structures has shown that the presence of $\mathrm{N}-\mathrm{H}$ bonds at the insulator/semiconductor interface plays a main role in the electrical behavior of the MIS structure. ${ }^{9}$ From the data of Refs. 10 and 11, it is suggested that the $\mathrm{N}-\mathrm{H}$ bonds may act as precursor sites for defect generation at the nitrided-SiO $/ \mathrm{Si}$ interface.

The electrical behavior of the $\mathrm{SiN}_{x}: \mathrm{H} / \mathrm{Si}$ interface is not as well known as the $\mathrm{SiO}_{2} / \mathrm{Si}$ interface. It is argued that the high intrinsic film stress is responsible for a high density of interfacial traps, ${ }^{12}$ resulting in poorer structures. Few papers dealing with the electrical characteristics of $\mathrm{SiN}_{x}: \mathrm{H} / \mathrm{Si}$ structures have been published. The microscopic origin of interfacial defects on these structures is not well known. ${ }^{13}$ Indeed, the use of $\mathrm{SiN}_{x}: \mathrm{H}$ films deposited by $\mathrm{ECR}$ in $\mathrm{SiN}_{x}: \mathrm{H} / \mathrm{Si}$ MIS devices is scarce. ${ }^{14,15}$ 
In view of the incleasing interest of $\mathrm{SiN}_{x}: \mathrm{H}$ interlayers in gate dielectric struciures, in this paper we will present a detailed study of the electrical characteristics of $\mathrm{SiN}_{x}: \mathrm{H} / \mathrm{Si}$ MIS devices in which the $\mathrm{SiN}_{x}: \mathrm{H}$ films are deposited by the ECR plasma method at low temperatures.

The aim of the paper is twofold:

(i) To analyze the properties of the $\mathrm{SiN}_{x}: \mathrm{H}$ films in relation to their use in MIS devices. The main emphasis is paid on the atomic bonding arrangement of films and on their electrical properties. These are analyzed by measuring the accumulation zone of $I-V$ characteristics of MIS structures.

(ii) To know details about the electrical characteristics of the $\mathrm{SiN}_{x}: \mathrm{H} / \mathrm{Si}$ interface, $C-V$ measurements and deep level transient spectroscopy (DLTS) characterizations are conducted on the devices. To the best of our knowledge, this technique is scarcely used to analyze $\mathrm{SiN}_{x}: \mathrm{H} / \mathrm{Si}$ MIS devices.

\section{EXPERIMENT}

The deposition system used in this study consists of an Astex 4500 ECR plasma source attached to a deposition chamber of our design. Microwave power $(2.45 \mathrm{GHz})$ was introduced into the source through a coaxial cable and a fused quartz window. $\mathrm{N}_{2}$ was used to generate the plasma and pure $\mathrm{SiH}_{4}$ was introduced into the deposition chamber through a gas dispersal ring. The deposition parameters which we chose to deposit the films were the microwave power $(50-200 \mathrm{~W})$, and the gases flux ratio $\mathrm{N}_{2} / \mathrm{SiH}_{4}(R$, in the following), with values comprised of between 0.5 and 9 . Pressure $(0.6 \mathrm{mTorr})$ and substrate temperature $\left(200^{\circ} \mathrm{C}\right)$ were kept constant in all the depositions. ${ }^{16}$

Film properties were analyzed with different techniques. The composition of the films, deposited on Si substrates, was measured by Auger electron spectroscopy (AES). Measurements were carried out in a JEOL JAMP-10S system. The Si $(L V V)$, and $\mathrm{N}(K L L)$ transitions were measured. To obtain the bulk composition, samples were sputtered with Ar ions of $2 \mathrm{kV}$, until a constant value of the Auger signals was reached. Then, quantitative results were obtained with the corresponding relative sensitivity factors. ${ }^{17}$ To avoid the influence of preferential resputtering effects, we used a reference sample in all the measurements.

Bonding configuration of the films was deduced with infrared absorption characterization. Measurements were obtained with a Fourier transform infrared (FTIR) Nicolet 5PC spectrometer in the midinfrared region $\left(400-4000 \mathrm{~cm}^{-1}\right)$, for films deposited on high-resistivity $(80 \Omega \mathrm{cm}) \mathrm{Si}$ substrates, both sides polished. The hydrogen concentration of the films, $[\mathrm{H}]$, was calculated from the $\mathrm{Si}-\mathrm{H}$ and $\mathrm{N}-\mathrm{H}$ stretching absorption peaks using the method of Lanford and Rand. ${ }^{18}$ The spin density of the films was determined by electron paramagnetic resonance (EPR) measurements, using a Bruker ESP 300E $X$-band spectrometer.

MIS devices were obtained as follows: the substrates used were $n$-Si $(5 \Omega \mathrm{cm},\langle 100\rangle$ orientation), in which we have previously deposited $\mathrm{Al}$ back electrodes by thermal evaporation. We cleaned the wafers with organic solvents. After this, the native oxide was stripped with a $\mathrm{H}_{2} \mathrm{O}: \mathrm{HF}$ (10:1) solution during $30 \mathrm{~s}$, followed by a $3 \mathrm{~min}$ rinse in

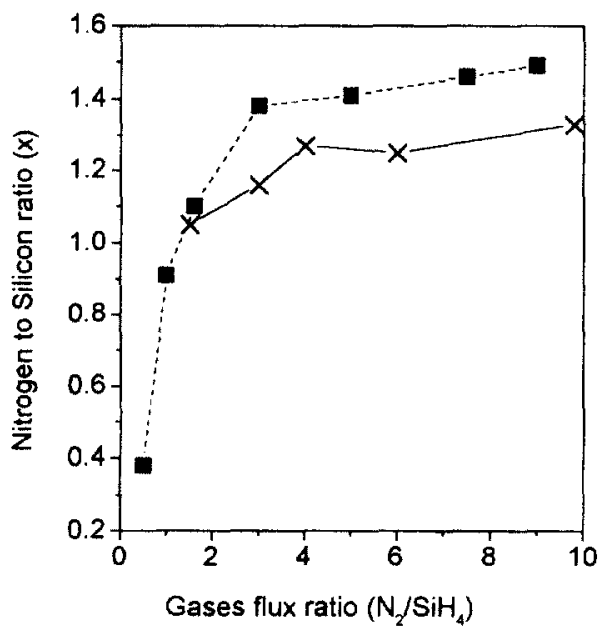

FIG. 1. Nitrogen to silicon ratio for the films as a function of the gas flux ratio $(R)$ ( $\square$ ). Also shown, the results of Ref. 1 for ECR films deposited at $500^{\circ} \mathrm{C}(X)$.

deionized water. ${ }^{19} 500 \AA$ thick $\mathrm{SiN}_{x}: \mathrm{H}$ film was then deposited on the top of the Si surface. Finally, Al dots were evaporated through a shadow mask to define square electrodes of $1.2 \times 10^{-3} \mathrm{~cm}^{2}$. A postdeposition annealing was done at $400^{\circ} \mathrm{C}$ during $20 \mathrm{~min}$ in a $\mathrm{N}_{2}$ atmosphere.

The electrical properties of the films (resistivity, $\rho$, and breakdown field, $E_{B}$ ) were obtained by measuring the $I-V$ characteristics of the MIS structures. The resistivity was obtained at an electric field of $2 \mathrm{MV} / \mathrm{cm} .{ }^{20}$ The value of $E_{B}$ was obtained at the field at which the MIS current reaches $1 \mu \mathrm{A} / \mathrm{cm}^{2}{ }^{2 !}$

$C-V$ characteristics [quasistatic (QS) and high frequency (HF) curves], were obtained with a Keithley Model 82 system. The analysis of the $C-V$ data was done following the procedure described by Nicollian and Brews. ${ }^{22}$

DLTS measurements were performed using a $1 \mathrm{MHz}$ Boonton 72B capacitance meter and an HP 54501A digital oscilloscope to record the complete capacitance transients. The quiescent bias voltage was introduced by a Keithley 617 programmable electrometer, and the filling pulses were introduced by an HP 214B pulse generator. Samples were cooled in darkness from room temperature to $100 \mathrm{~K}$ at zero bias in an Oxford DN1710 cryostat.

The interface-state profiles were obtained by saturating pulse DLTS. ${ }^{23,24}$ The bias voltage was chosen so that the MIS capacitor was just at the limit between depletion and weak inversion. A $10-\mathrm{ms}$ wide pulse high enough to drive the capacitors into accumulation was applied in order to fill all interface traps. Information on the traps was obtained by analyzing the capacitance transient that results as the traps empty, i.e., return to equilibrium.

\section{RESULTS AND DISCUSSION}

The main deposition parameter that determines the film properties was the gas flux ratio, $R \cdot{ }^{25}$ In Fig. 1, we show the $\mathrm{N} / \mathrm{Si}$ ratio of films (in the following, $x$ ) as a function of $R$, for films deposited at $100 \mathrm{~W}$ (the same power that we chose to obtain the MIS structures). As a comparison, we present in the same figure the results of Park, ${ }^{1}$ for films of $\mathrm{SiN}_{x}: \mathrm{H}$ 


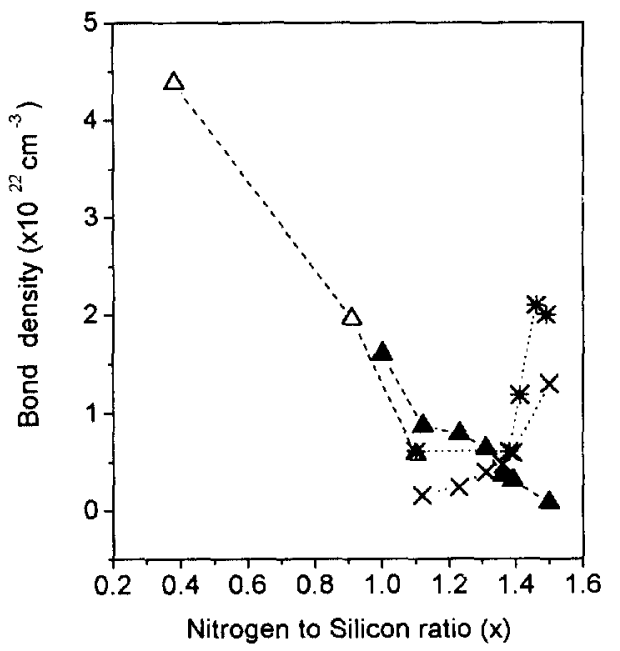

FIG. 2. Concentration of $\mathrm{Si}-\mathrm{H}(\triangle)$ and $\mathrm{N}-\mathrm{H}(*)$ bonds of the films as a function of film composition, $x$. We also present the concentration of $\mathrm{Si}-\mathrm{H}$ bonds $(\Lambda)$ and the $\mathrm{N}-\mathrm{H}$ bonds $(\times)$ for films of $\mathrm{SiN}_{x}: \mathrm{H}$ deposited by PECVD at $250^{\circ} \mathrm{C}$ (Ref. 26).

obtained by ECR and using the same precursor gases as those utilized in this study. The main difference is in relation with the deposition temperature $\left[200^{\circ} \mathrm{C}\right.$ for our films, $500{ }^{\circ} \mathrm{C}$ for the data of $\mathrm{Park}^{1}$ ]. From the figure, it can be deduced that we obtained $\mathrm{SiN}_{x}: \mathrm{H}$ films with a wide range of compositions, with values of $x$ ranging from $x \leqslant 0.91$ (at $R$ $\leqslant 3$ ), to $x \geqslant 1.45$ (at $R \geqslant 7.5$ ). The trend is similar to the data of Park $e t$ al., ${ }^{1}$ with slight differences on the absolute values.

In Fig. 2, we present the concentration of $\mathrm{Si}-\mathrm{H}$ and $\mathrm{N}-\mathrm{H}$ bonds of the films, as a function of $x$. Si-H bonds are dominant in Si-rich films, whereas $\mathrm{N}-\mathrm{H}$ bonds are observed in $\mathrm{N}$-rich films. This trend is well known to hold in $\mathrm{SiN}_{x}: \mathrm{H}$ films deposited by plasma methods. ${ }^{26}$ The comparison with other results is difficult, because of the different precursor gases, deposition temperature, and other process parameters used in the deposition. These parameters have a main influence on the bonding arrangement and on the total amount of hydrogen of the films. Anyway, we have included in Fig. 2 the data of Parsons, ${ }^{26}$ for PECVD films that were deposited with the same precursor gases and very similar deposition temperature $\left(250^{\circ} \mathrm{C}\right)$ to those reported here. The transition from films dominated by $\mathrm{Si}-\mathrm{H}$ bonds to those dominated by $\mathrm{N}-\mathrm{H}$ occurs at a film composition of $x \sim 1.3$ for both set of data. Depending on the plasma reactor and on the deposition conditions, the results may vary in a relatively wide range. ${ }^{27}$ Our data indicate that for compositions ranging from $x$ $=1.1$ to $x=1.4$, the total amount of bonded hydrogen (deduced from the concentrations of $\mathrm{Si}-\mathrm{H}$ and $\mathrm{N}-\mathrm{H}$ bonds) remains around 10 at. $\%$ and, at the film composition with $x=1.38$, this amount is as low as 6 at. \%. This result is among the better ones reported in the literature for $\mathrm{SiN}_{x}: \mathrm{H}$ films deposited for any plasma method at low deposition temperature.

The $I-V$ characteristic of the MIS structures are similar to those showed in Ref. 28 for films also deposited by ECR. We have not accomplished a detailed analysis of these characteristics being used by the data in this study to obtain the

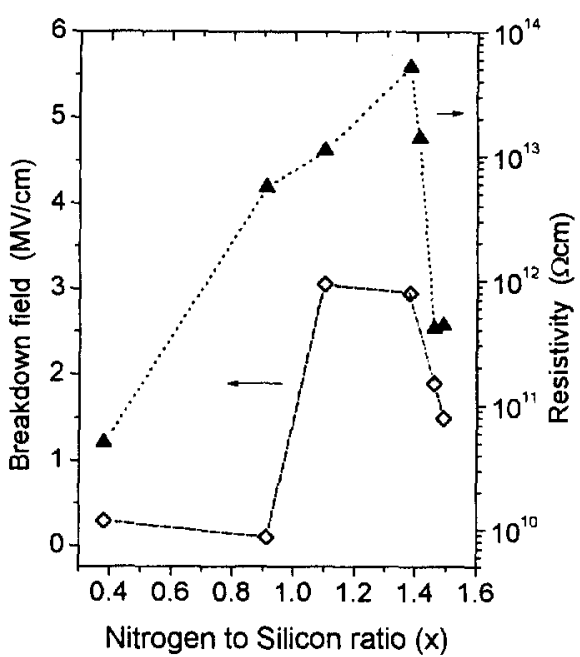

FIG. 3. Electric breakdown field $(\diamond)$ and resistivity of films $(\boldsymbol{\Delta})$ as a function of $x$.

value of the resistivity, as we have explained in Sec. II.

In Fig. 3, we present the values of the electric breakdown field, $E_{B}$, and the film resistivity, $\rho$, as a function of film composition, $x$. The maximum of both parameters is obtained at film compositions that range from $x=1.1$ to $x$ $=1.41$. On the other hand, in films with composition far from this range, both $E_{B}$ and $\rho$ values fall down. At the composition with $x=1.38$, the values of $E_{B}$ and $\rho$ are 3 $\mathrm{MV} / \mathrm{cm}$ and $6 \times 10^{13} \Omega \mathrm{cm}$, respectively. The values of the resistivity indicates that the films are not "perfect" insulators. The presence of defects of a diverse nature may account for the values of $\rho$ presented in Fig. 3 that are lower than those obtained in pyrolitic CVD silicon nitride but similar to the values reported in films obtained with plasma CVD techniques in which the deposition temperature was higher than that used in this study. ${ }^{15}$ We will subsequently analyze the defects present in the films.

Figures 2 and 3 indicate that in the films that show poor values of the electrical parameters, i.e., in the films with the parameter $x$ lower than 1.1 or higher than $1.41,[\mathrm{H}]$ is high. The relation between $E_{B}$ and the presence of hydrogen in the films was fairly suggested by Hasegawa ${ }^{29}$ for films deposited by PECVD; however an unambiguous relation never has been established. The stress of the films, directly related with the presence/absence of hydrogen, may play some specific role in the understanding of breakdown properties of $\operatorname{SiN}_{x}: \mathrm{H}$ films.

In relation with the film resistivity, in Fig. 4 we present the dependence of this parameter and also the dependence of $[\mathrm{H}]$ with the composition, $x$. As in the case of $E_{B}$, a close relation between both parameters seem to hold. Although some papers have been published trying to explain the relation between $\rho$ and $[\mathrm{H}],{ }^{20}$ a definitive model has not yet been established, as in the case of the relation $E_{B}-[\mathrm{H}]$.

The main conclusion found from Figs. 3 and 4 is that in a relatively wide range of film compositions (from $x=1.1$ to $x=1.4$ ), we may obtain $\operatorname{SiN}_{x}: \mathrm{H}$ films with electrical properties similar to those obtained with plasma deposition meth- 


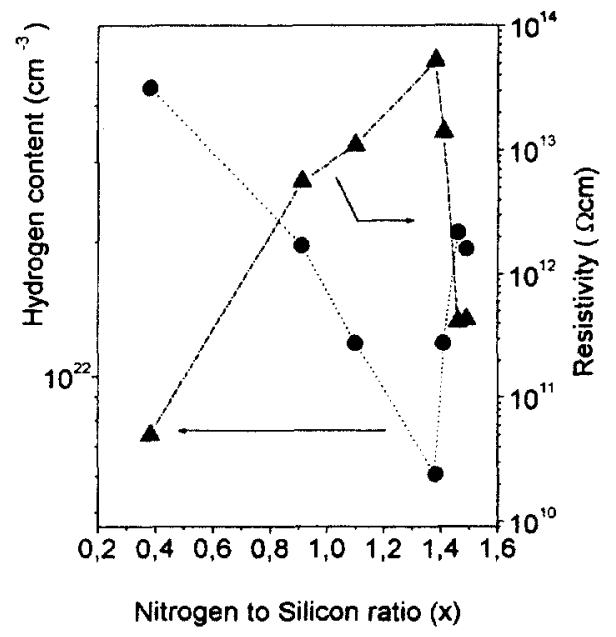

FIG. 4. Resistivity (A) and hydrogen content (๑) as a function of $x$.

ods which use higher substrate temperatures than the value used in this study.

In Fig. 5, we present the $C-V$ characteristic (both QS and HF curves) for a MIS in which the film composition is $x=1.38$. The dip observed in the QS curve is a clear indication of the high quality of the $\mathrm{SiN}_{x}: \mathrm{H} / \mathrm{Si}$ interface.

From the data of the flatband voltage, we have deduced the values of the fixed trapped charge at the insulator $\left(Q_{i}\right)$. This was always positive, as it is commonly reported in $\mathrm{SiN}_{x}: \mathrm{H}_{\text {films. }}{ }^{7}$ In Fig. 6 , we have plotted the values of $Q_{i}$ and the spin density of the bulk of the films, deduced from EPR measurements, ${ }^{30}$ as a function of the composition, $x$. It is worth noting that EPR measurement accounts for the presence of defects that are paramagnetically active both in the bulk of the insulator and also at the interface with the $\mathrm{Si}$ substrate. Since our films are defective, the contribution to the EPR signal coming from defects located at the $\mathrm{SiN}_{x}: \mathrm{H} / \mathrm{Si}$ interface should be a small fraction of the total measurement signal. We then conclude that the EPR characterization al-

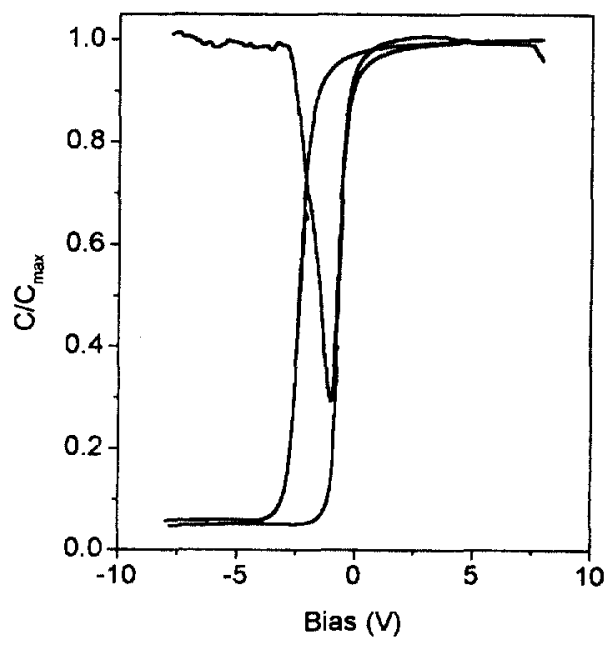

FIG. 5. Quasistatic and high frequency $C-V$ curves for a structure with an insulator with $x=1.38$.

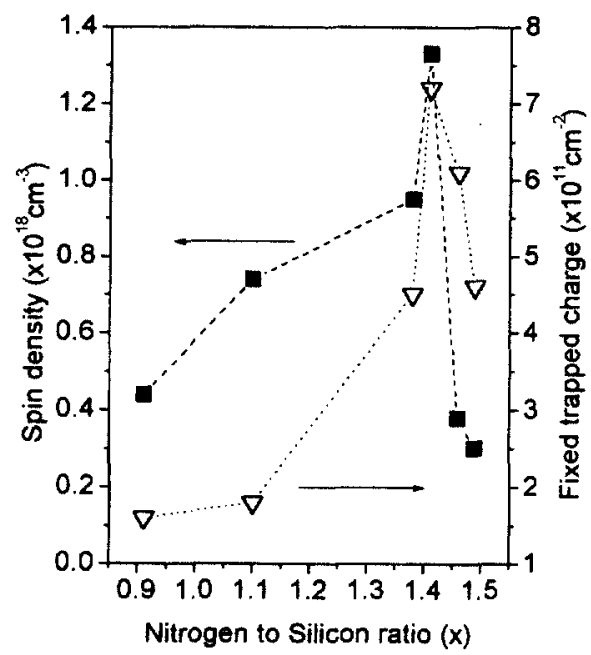

FIG. 6. Fixed trapped charge at the insulator $(\nabla)$ and spin density $(\mathbf{})$, as a function of $x$.

lows us to obtain the density of defects (paramagnetically active) present in the bulk of the insulator. Only if the insulator is free of defects (for instance, thermally grown $\mathrm{SiO}_{2}$ onto $\mathrm{Si}$ ), the EPR characterization can be used with care to obtain information concerning the presence of defects at the insulator/semiconductor interface. ${ }^{31}$

The trend with $x$ shown by both the spin density and $Q_{i}$ is very similar for both parameters. The behavior of the spin density was already explained elsewhere. ${ }^{30}$ The origin of such a defect is the well-known Si dangling bond $\left(\cdot \mathrm{Si} \equiv \mathrm{Si}_{3}\right)$, present in the bulk of the insulator. As the film composition changes from $x=0.91$ to $x=1.38$ the Si dangling bonds will be easily formed by breaking $\mathrm{Si}-\mathrm{Si}$ bonds. ${ }^{27}$ At compositions around $x=1.4$, the spin density and $Q_{i}$ reach their maximum value. Notice that at this composition, the presence of hydrogen at the films is minimum. Due to this fact, the number of unpassivated Si dangling bonds should reach their maximum concentration, as shown in Fig. 6 . Once the films become $\mathrm{N}$ rich, there is a sharp increase in the presence of $\mathrm{N}-\mathrm{H}$ bonds (see Fig. 2). These bonds induce a decrease in the concentration of Si dangling bonds, as was suggested by Hasegawa. ${ }^{27}$ This fact explains the sharp decrease observed in Fig. 6 for the spin density. The fact that $Q_{i}$ follows the same dependence with $x$ of the spin density, allows us to tentatively identify the microscopic origin of the fixed trapped charge $Q_{i}$, with the Si dangling bonds. However, some caution should be taken in this assignment. The technique EPR gives a direct measurement of defects that are paramagnetically active. Other type of defects not detectable by EPR like neutral defects, dangling bonds with two unsaturated bonds, can also contribute to $Q_{i}$. From Fig. 6, it seems that the main contribution to $Q_{i}$ comes from the $\mathrm{Si}$ dangling bonds.

In Fig. 7 , we present the hysteresis ( $\Delta V_{\text {hys }}$ ) of the curve $C-V$ as a function of the film composition, $x$. As known, films with low values of $x$ present high values for this parameter, whereas films with $x$ higher than 1.3 usually exhibit lower ones. ${ }^{21}$ 


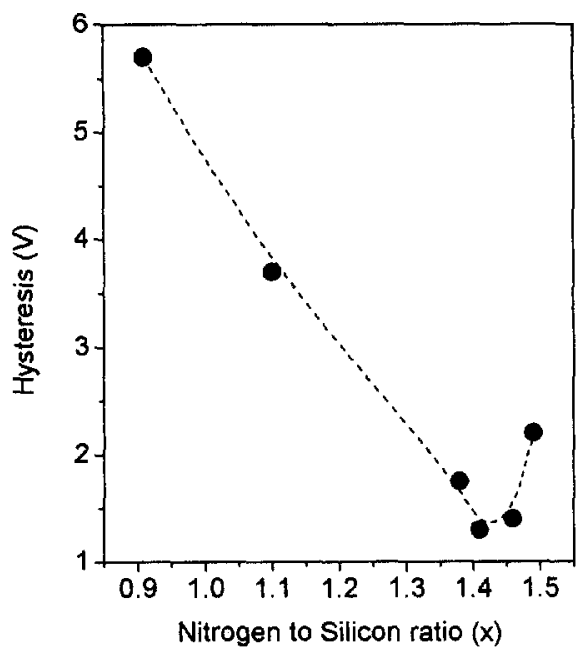

FIG. 7. Voltage hysteresis for the MIS analyzed, as a function of film composition, $x$.

On the other hand, we have deduced the distribution of the interface trap density within the forbidden gap $\left(D_{i t}\right)$ by means of $C-V$ and DLTS measurements. The distribution of $D_{i t}$ is obtained from the curves $C-V$ by means of the equation: ${ }^{22}$

$$
C_{i t}=q D_{i t}=\left(1 / C_{\mathrm{LF}}-1 / C_{1}\right)^{-1}-\left(1 / C_{\mathrm{HF}}-1 / C_{1}\right)^{-1},
$$

where $C_{\mathrm{LF}}, C_{\mathrm{HF}}$ are the values of the capacitance (per unit of area) of the MIS at low and high frequency, respectively, and $C_{1}$ is the capacitance of the insulator. We show in Fig. 8 the result of this analysis for the device in which the composition of the insulator is $x=1.38$, i.e., for the structure presented in Fig. 5. The minimum value of $D_{i t}$ appears around $0.15 \mathrm{eV}$ above the midgap, similar to the results reported by Sitbon ${ }^{15}$ for $\mathrm{SiN}_{x}: \mathrm{H} / \mathrm{Si}$ devices in which the insulator was deposited by distributed ECR. From the figure, it can be seen

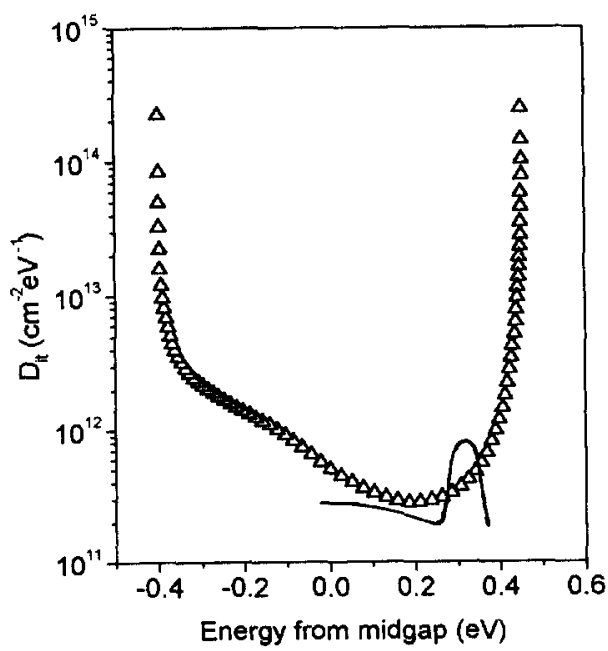

FIG. 8. Interface trap distribution within the forbidden gap deduced from the $C-V$ data $(\triangle)$, and from the DLTS measurements (---). The film composition is $x=1.38$. that the density of traps remains below $10^{12} \mathrm{~cm}^{-2} \mathrm{eV}^{-1}$ in a wide range of energies. This further supports the good quality of the interface.

For the calculation of $D_{i t}$ from DLTS spectra, the following expressions were used: ${ }^{22}$

$$
\begin{aligned}
& N_{S S}=\frac{\epsilon_{s} N_{D}}{K T} \frac{C_{I}\left[C\left(t_{2}\right)-C\left(t_{1}\right)\right]}{\left[C\left(t_{1}\right)\right]^{3}} \frac{1}{\ln \left(t_{2} / t_{1}\right)} \\
& E=E_{C}-K T \ln \sigma_{n}(E) v_{t h} N_{C} \frac{t_{2}-t_{1}}{\ln \left(t_{2} / t_{1}\right)},
\end{aligned}
$$

where $C(t)$ is the capacitance at time $t, C_{I}$ is the capacitance of the insulator, $\sigma_{n}$ is the interface state capture cross section, $v_{t h}$ is the thermal velocity of electrons, and $N_{c}$ is the effective density of states of the conduction band. An energy-independent capture cross-section value of $\sigma_{n}=1$ $\times 10^{-14} \mathrm{~cm}^{-2}$ was used in the calculation, which is typically found in Si-MIS structures. ${ }^{22,32}$

Figure 8 also shows that the interface states profile of the device where $x=1.38$ (i.e., the device showed in Fig. 5), is obtained by DLTS. We can observe the presence of a maximum located at about $0.3 \mathrm{eV}$ above the midgap $(0.25 \mathrm{eV}$ below the edge of the conduction band). This peak has been found in all the samples of our study, and it can be identified with the $P_{b N 0}$ defect. This defect was reported by Stesmans ${ }^{13}$ as the $\cdot \mathrm{Si} \equiv \mathrm{Si}_{3}$ defect in $\mathrm{Si} / \mathrm{Si}_{3} \mathrm{~N}_{4}$ interface, i.e., the surface $\mathrm{Si}$ dangling bond (also described in this paper as the unpaired hybrid pointing out the Si surface). The origin of this defect is the same as the origin of the $P_{b 0}$ defect in the $\mathrm{Si} / \mathrm{SiO}_{2}$ interface. ${ }^{33}$ The concentration of $P_{b \mathrm{~N} 0}$ centers present at the $\mathrm{SiN}_{x}: \mathrm{H} / \mathrm{Si}$ interface is then deduced from the data of Fig. 8 in a straightforward way.

In comparing the interface state profiles obtained by $C-V$ and DLTS, we can see that the shape of the distribution is different, though both techniques provide values for the interface trap density of the same order of magnitude. Differences between $C-V$ and DLTS measurements can be accounted for by the presence of slow states at the insulator/ semiconductor interface, i.e., defects that are somewhat distributed away from the interface into the insulator. When the interface states are distributed in such a way, the electron emission and capture processes involve both thermal excitation and tunneling, producing a broad time constant dispersion, thus affecting the interface trap distribution obtained by $C-V$ and DLTS measurements in different ways, ${ }^{34,35}$ thus justifying the shape of trap distribution of Fig. 8. The hysteresis observed in $C-V$ curves (Fig. 7) should be in relation with the above-mentioned processes. To further confirm the presence of such slow states, we have performed conductance transient measurements of the devices. These transients appear in a wide temperature range ( $200 \mathrm{~K}$ to room temperature), and their shape is very dependent on the measurement frequency. Elsewhere we have explained ${ }^{36}$ that these transients in terms of tunneling assisted emission and capture processes of electrons between the semiconductor conduction band and the interface states located far away from the interface up to distances of at least $30 \AA$. This further confirms the previous discussion. 


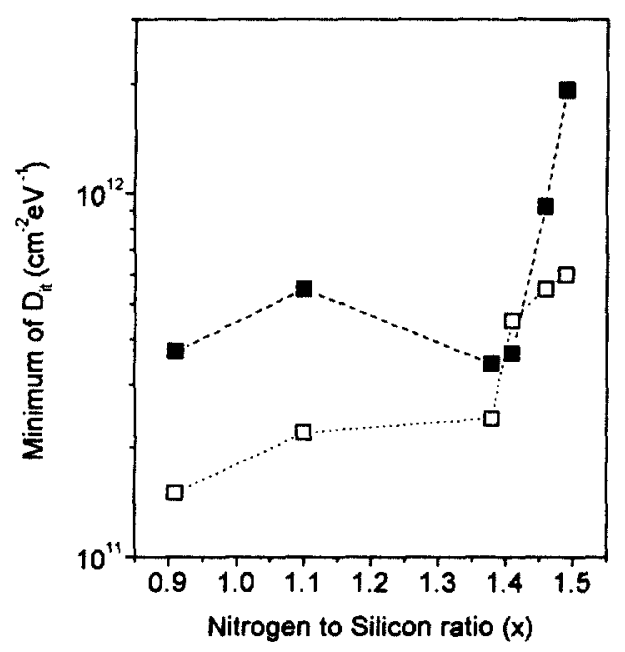

FIG. 9. Minimum value of $D_{i t}$ as a function of $x$, deduced from $C-V$

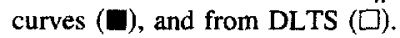

In Fig. 9, we present the minimum of $D_{i t}$ (deduced from $C-V$ measurements) as a function of film composition, and the values of this parameter obtained from the DLTS at the same energy at which the minimum of the $C-V$ curve appears. The trend shown by the two sets of data is coincident. For film compositions lower than $x=1.38$, the minimum of $D_{i t}$ is a slight function of $x$. For this range of compositions, the values of $D_{i t}$ are below $5 \times 10^{11} \mathrm{~cm}^{-2} \mathrm{eV}^{-1}$ and the typical value is $(2-3) \times 10^{11} \mathrm{~cm}^{-2} \mathrm{eV}^{-1}$. This is among the lower values described for the $\mathrm{SiN}_{x}: \mathrm{H} / \mathrm{Si}$ interface. The devices with $\mathrm{SiN}_{x}: \mathrm{H}$ films in which $x>1.4$, exhibit a sharp increase in the values of $D_{i t}$, i.e., the interface becomes more defective.

The results we present in Fig. 9 can be understood on the basis of the role that $\mathrm{N}-\mathrm{H}$ bonds play in the behavior of the interface between $\mathrm{SiN}_{x}: \mathrm{H}$ and $\mathrm{Si}$, according to the model of Lucovsky. ${ }^{10,11}$ Although this model was developed to explain the electrical characteristics of (oxide-nitrideoxide)/Si interfaces, ${ }^{8}$ we think that their main conclusions also hold for $\mathrm{SiN}_{x}: \mathrm{H} / \mathrm{Si}$ devices. In fact, in Fig. 10 we plot the minimum of the interface trap density (deduced from the $C-V$ curves), and the concentration of $\mathrm{N}-\mathrm{H}$ bonds, as a function of the film composition. We have also plotted in the same figure the concentration of $P_{b \mathrm{NO}}$ centers. As was explained in the previous paragraph, this parameter accounts for the number of dangling bonds with the unpaired hybrid pointing out the Si surface, i.e., the number of interface defects of the type $\cdot \mathrm{Si} \equiv \mathrm{Si}_{3}$. From Fig. 10, the dependence of the three parameters with the composition is very similar: for compositions below $x \approx 1.4$, all of them remain roughly constant. For values of $x$ higher than 1.4, the three increase sharply. Notice that the rise observed in $D_{i t}$ and in $P_{b \text { NO }}$ parallels the increase of the concentration of $\mathrm{N}-\mathrm{H}$ bonds.

Following the model of Lucovsky, ${ }^{10,11}$ the presence at the $\mathrm{SiN}_{x}: \mathrm{H} / \mathrm{Si}$ interface of a $\mathrm{N}-\mathrm{H}$ bond located in the vicinity of a $\mathrm{Si}-\mathrm{H}$ surface terminated bond, promotes the formation of a N- $\mathrm{H}_{2}$ bond (via the trapping of a hole). This process gives rise to the formation of a dangling bond of the type $\cdot S i \equiv \mathrm{Si}_{3}$, i.e., to the formation of $P_{b \mathrm{~N} 0}$ centers. The

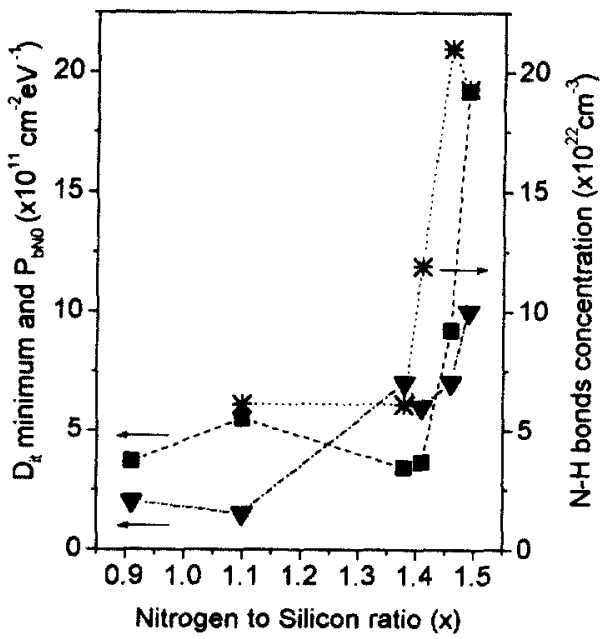

FIG. 10. Minimum value of $D_{\text {it }}$ [deduced from $C-V$ characterization ( $\left.\square\right)$ ], concentration of $P_{b \mathrm{~N} 0}$ centers $(\nabla)$ and concentration of $\mathrm{N}-\mathrm{H}$ bonds $(*)$, as a function of film composition, $x$.

dependence of the concentration of these centers with the film composition (Fig. 9) and the close relation between this concentration and the $\mathrm{N}-\mathrm{H}$ bonds (Fig. 10) seems to confirm this explanation.

From the results of Figs. 7, 9, and 10, we deduce that $\mathrm{N}-\mathrm{H}$ bonds have the main influence on the electrical characteristics of $\mathrm{Al} / \mathrm{SiN}_{x}: \mathrm{H} / \mathrm{Si}$ MIS capacitors. This influence is different depending on the location of these bonds. When they are in the bulk of the insulator, they promote the decrease of Si dangling bonds and the decrease of the fixed trapped charge at the insulator, $Q_{i}$. On the other hand, $\mathrm{N}-\mathrm{H}$ bonds at the interface with the semiconductor act as a precursor site to defect generation of the type of Si dangling bonds. As a consequence, the interface is more defective as the concentration of the $\mathrm{N}-\mathrm{H}$ bonds increases.

As a final comment, we wish to state that one year after we fabricated the structures, their behavior remains essentially unchanged, which proves the quality of the procedure we followed to obtain them

\section{CONCLUSIONS}

We have deposited thin films of $\mathrm{SiN}_{x}: \mathrm{H}$ by the ECR plasma method at a deposition temperature of $200^{\circ} \mathrm{C}$. The films present a low content of bonded hydrogen. In the range of compositions from $x=1.1$ to $x=1.4$, the parameter is around 10 at. $\%$, and at film composition $x=1.38$, is 6 at. $\%$. This qualifies the films to be used as the gate dielectric in MIS devices. The electrical properties of films (resistivity and electric breakdown field) are strongly in influenced by the film composition and by the hydrogen content. The best values attained for these two parameters are obtained for films with $x=1.38$, in which the content of hydrogen is minimum.

From the $C-V$ characterization of the devices, we deduced that the fixed trapped charge at the insulator is dominated by the bonding arrangement of the films. The films that present significant amounts of $\mathrm{N}-\mathrm{H}$ bonds, have low values 
of fixed trapped charge. Also, the density of bulk dangling bonds deduced from EPR measurements follows the trend of the trapped charged with the composition of the insulator. These facts seem to indicate that the presence of $\mathrm{N}-\mathrm{H}$ bonds are the main influence in the reduction of the charge of the insulator bulk.

The interface trap distribution of the devices, deduced from $C-V$ and DLTS measurements, showed a similar behavior with small differences coming from the different procedures of measurement. These differences are explained taking into account both the energy and the spatial distribution of the interface states, i.e., taking into account the presence of slow states at the insulator/semiconductor interface. We deduced a close relation among the minimum of the interface trap density, the concentration of $P_{b \mathrm{~N} 0}$ centers and the concentration of $\mathrm{N}-\mathrm{H}$ bonds in the films. These bonds, located at the $\mathrm{SiN}_{x}: \mathrm{H} / \mathrm{Si}$ interface, act as precursor sites to defect generation of the type $\cdot \mathrm{Si}_{\mathrm{Si}_{3}}$, i.e., the center $P_{b \mathrm{~N} 0}$. These sets of results are in close agreement with the model of Lucovsky. ${ }^{10,11}$ Also, we conclude the different influence that $\mathrm{N}-\mathrm{H}$ bonds have, depending on if we consider their influence in the bulk of the insulator or at the interface with the semiconductor.

The results we have presented here could be a significant advance in the comprehension of the behavior of $\mathrm{SiN}_{x}: \mathrm{H} / \mathrm{Si}$ devices.

\section{ACKNOWLEDGMENTS}

The authors would like to thank E. Iborra for the facilities of the infrared characterization of the films. This work was partially supported by the Spanish Government (CICYT), under Grant TIC 93/0175.

${ }^{1}$ D. G. Park, M. Tao, D. Li, A. E. Botchkarev, Z. Fan, Z. Wang, S. N. Mohammed, A. Rockett, J. R. Abelson, and H. Morkoc, J. Vac. Sci. Technol. B 14, 2674 (1996).

${ }^{2}$ K. H. Chew, J. Chen, R. C. Woods, and J. L. Sohet, J. Vac. Sci. Technol. A 13, 2483 (1995).

${ }^{3}$ R. I. Hegde, P. J. Tobin, K. G. Reid, B. Maiti, and S. A. Ajuria, Appl. Phys. Lett. 66, 2882 (1995).

${ }^{4}$ A. Kapila, X. Si, and V. Malhotra, Appl. Phys. Lett. 62, 2259 (1993).

${ }^{5}$ P. J. M. Permiter and J. G. Swanson, J. Electron. Mater. 25, 1506 (1996).

${ }^{6}$ Z. Lu, S. S. He, Y. Ma, and G. Lucovsky, J. Non-Cryst. Solids 187, 340 (1995)
${ }^{7}$ Y. Ma, T. Yasuda, and G. Lucovsky, J. Vac. Sci. Technol. A 11, 952 (1993).

${ }^{8}$ Y. Ma, T. Yasuda, and G. Lucovsky, Appl. Phys. Lett. 64, 2226 (1994).

${ }^{9}$ D. R. Lee, G. Lucovsky, M. S. Denker, and C. Magee, J. Vac. Sci. Technol. A 13, 1671 (1995).

${ }^{10}$ Z. Ying, G. Lucovsky, and J. L. Whitten, J. Vac. Sci. Technol. B 13, 1613 (1995).

${ }^{11}$ G. Lucovsky, Z. Ying, and D. R. Lee, J. Vac. Sci. Technol, B 14, 2832 (1996).

${ }^{12}$ R. C. Budhani, R. F. Bunshah, and P. A. Finn, Appl. Phys. Lett. 52, 284 (1988).

${ }^{13}$ A. Stesmans, Semicond. Sci. Technol. 4, 1000 (1989).

${ }^{14}$ D. Landheer, J. A. Bardwell, I. Spraule, J. Scott-Thomas, W. Kwok, and W. M. Lau, Can. J, Phys. 70, 795 (1992).

${ }^{15} \mathrm{~S}$. Sitbon, M. C. Hugon, B. Agius, F. Abel, J. L. Courant, and M. Puech, J. Vac. Sci. Technol. A 13, 2900 (1995).

${ }^{16}$ S. Garcia, J. M. Martin, I. Martil, M. Fernandez, and G. Gonzalez Diaz, Philos. Mag. B 73, 487 (1996).

${ }^{17}$ Handbook of Auger Electron Spectroscopy, 2nd ed. (Physical Electronics Industries, Eden Prairie, MN, 1976).

${ }^{18}$ W. A. Lanford and M. J. Rand, J. Appl. Phys. 49, 2473 (1978).

${ }^{19}$ L. J. Huang and K. M. Lau, Appl. Phys. Lett. 60, 1108 (1992).

${ }^{20}$ M. Maeda and Y. Arita, J. Appl. Phys. 53, 6852 (1982).

${ }^{21}$ W. S. Lau, S. J. Fonash, and J. Kanicki, J. Appl. Phys. 66, 2765 (1989).

${ }^{22}$ E. H. Nicollian and J. R. Brews, MOS Physics and Technology (Wiley, New York, 1982).

${ }^{23}$ D. V. Lang, J. Appl. Phys. 45, 3023 (1974).

${ }^{24}$ M. Schulz and N. M. Johnson, Appl. Phys, Lett. 31, 622 (1977).

${ }^{25}$ S. Garcia, J. M. Martin, M. Fernandez, I. Martil, E. Iborra, and G. Gonzalez Diaz, J. Non-Cryst. Solids 187, 329 (1995).

${ }^{26}$ G. N. Parsons, J. H. Sank, and J. Batey, J. Appl. Phys. 70, 1553 (1991).

${ }^{27}$ S. Hasegawa, Y. Amano, T. Inokuma, and Y. Kurata, J. Appl. Phys. 72, 5676 (1992); S. Hasegawa, M. Matsuda, and Y. Kurata, Appl. Phys. Lett. 58, 741 (1991).

${ }^{28}$ Y. C. Jean, H. Y. Lee, and S. K. Jao, J. Appl. Phys. 75, 979 (1994).

${ }^{29}$ S. Hasegawa, Y. Amano, T. Inokuma, and Y. Kurata, J. Appl. Phys. 75, 1493 (1994).

${ }^{30}$ S. Garcia, D. Bravo, M. Fernandez, I. Martil, and G. Gonzalez Diaz, Appl. Phys. Lett. 67, 3263 (1995)

${ }^{31}$ E. H. Poindexter, G. J. Gerardi, M. E. Bueckel, P. J. Caplan, M. M. Johnson, and D. K. Biegelsen, J. Appl. Phys. 56, 2844 (1984).

${ }^{32}$ Y. Yamasaki, M. Ooshida, and T. Sugano, Jpn. J. Appl. Phys. 18, 113 (1979).

${ }^{33}$ R. Helms and E. H. Poindexter, Rep. Prog. Phys. 57, 791 (1994).

${ }^{34} \mathrm{~T}$. Hashizume, H. Hasegawa, R. Riemenschneider, and H. L. Hartnagel, Jpn. J. Appl. Phys., Part 1 33, 727 (1994).

${ }^{35}$ H. Hasegawa, M. Akazawa, H. Ishii, A. Uraie, H. Iwadate, and E. Ohue, J. Vac. Sci. Technol. B 8, 867 (1990).

${ }^{36}$ S. Dueñas, R. Pelaez, E. Castan, R. Pinacho, L. Quintanilla, J. Barbolla, I. Martil, and G. Gonzalez Diaz, Appl. Phys. Lett. 71, 826 (1997). 